\title{
Effect of betaine and ascorbic acid in drinking water on growth performance and blood biomarkers in meat ducks exposed to heat stress
}

\author{
J-S. Shin, K-H. Um*, H-J. Park, Y-S. Choi, H-S. Lee \& B-S. Park \\ College of Animal Life Science, Kangwon National University, Chuncheon, Gangwondo, 24419 \\ Republic of Korea
}

(Received 21 February 2019; Accepted 17 March 2019; First published online 11 May 2019)

\author{
Copyright resides with the authors in terms of the Creative Commons Attribution 4.0 South African License. \\ See: http://creativecommons.org/licenses/by/4.0/za \\ Condition of use: The user may copy, distribute, transmit and adapt the work, but must recognize the authors and \\ the South African Journal of Animal Science
}

\begin{abstract}
The aim of this study was to compare the effect of drinking water that contains various levels of ascorbic acid (AA) and betaine (BT) on growth performance and blood biomarkers in meat ducks exposed to heat stress. Six hundred and forty one-day-old Cherry Valley ducks were randomly assigned to one of seven treatment groups: i) control group, drinking water without ascorbic acid or betaine, ii) AA100, drinking water containing ascorbic acid at 100 milligrams per litre, iii) AA200, drinking water containing ascorbic acid at 200 milligrams per litre, iv) AA300, drinking water containing ascorbic acid at 300 milligrams per litre, v) BT400, drinking water containing betaine at 400 milligrams per litre, vi) BT800, drinking water containing betaine at 800 milligrams per litre, and vii) BT1200, drinking water containing betaine at 1200 milligrams per litre. The ducks were exposed to heat stress $\left(11: 00\right.$ to $17: 00,33{ }^{\circ} \mathrm{C}$ to $43{ }^{\circ} \mathrm{C}$, relative humidity $70 \%$, artificially controlled-environment houses) from the 22nd to 42 nd days. Ducks from treatment groups AA300 and BT1200 displayed significantly increased bodyweight gains compared with those in the control group. Blood levels of glucose, and activities of aspartate aminotransferase and alanine aminotransferase in all treatment groups were significantly lower than those observed in the control group. Red blood cell count, platelet number, electrolytes and blood gas concentrations were significantly higher in all treatment groups compared with those in the control group. Blood $\mathrm{pH}$ levels in all treatment groups were lower than those in the control group. In conclusion, drinking water containing ascorbic acid or betaine improved the growth performance via biomarker homeostasis in blood of meat ducks exposed to heat stress.
\end{abstract}

Keywords: body weight gain, blood lipid, red blood cell, electrolytes; blood gas, blood pH

\# Corresponding authors: bspark@kangwon.ac and kracopop9969@naver.com

\section{Introduction}

Heat stress during summer jeopardizes animal well-being and decreases their productivity by activating physical stress mechanisms (Gaughan et al., 2013; Sharma et al., 2013). Providing broiler chickens under heat stress with feed that contains ascorbic acid may improve energy metabolism regulation, collagen biosynthesis, heart health and blood flow by relaxing blood vessels to reduce the stress (Boyera et al., 1998; Yoon et al., 2013). The addition of $200 \mathrm{mg}$ to $250 \mathrm{mg}$ ascorbic acid/kg feed or drinking water of broiler chickens under heat stress may also improve their growth performance (Sahin et al., 2003; Kadim et al., 2008). However, such studies have not been performed in ducks. Betaine, a trimethyl derivative of glycine, is an amphipathic compound that has three hydrophobic methyl groups and a hydrophilic carboxyl group. It acts as an in vivo donor of choline, methionine and methyl groups (Del Vesco et al., 2014). Betaine is involved in protein synthesis and energy metabolism. It can improve the growth performance of animals by mitigating damage caused by heat stress (Ratriyanto et al., 2009). Betaine improves growth performance by regulating the osmotic pressure in animals under heat stress to prevent dehydration, maintain water content in cells, save energy and enhance nutrient bioavailability (Mahmoudnia \& Madani, 2012). It has been reported that the bodyweight of broiler chickens under heat stress is increased by adding $800 \mathrm{mg}$ to $1000 \mathrm{mg}$ betaine $/ \mathrm{kg}$ feed or $0.05 \%$ to $0.2 \%$ betaine to drinking water (Ratriyanto et al., 2009). Providing feed that contains $1.5 \%$ betaine to duck layers during summer has been reported to improve egg production (Awad et al., 2014). 
In previous studies, the authors verified that providing meat ducks that are exposed to heat stress during summer with feed that contains betaine can help them maintain their blood profile homeostasis and relieve their stress by increasing short chain fatty acids in the caecal contents, thus improving their productivity (Bang et al., 2015; Hwangbo et al., 2015). This study was conducted to investigate the effect of supplemental drinking water with betaine or ascorbic acid on growth performance and blood biomarkers in meat ducks under heat stress.

\section{Materials and Methods}

Animal experimental procedures conformed to the scientific and ethical regulations provided in EEC Directive of 1986; 86/609/EEC. They were approved by the Institutional Animal Care and Use Committee of Kangwon University (KW-141027-1). A total of 640 Cherry Valley (Anas platyrhynchos) meat ducks was obtained from a hatchery in Yangpyeong, South Korea. The experiment followed a completely randomized design ( 7 treatments, 6 replications per treatment, 15 ducks per $5.2 \mathrm{~m}^{2}$ pen). The seven treatment groups consisted of the control group, which was provided with drinking water without ascorbic acid (AA) and betaine (BT), and treatment groups that were provided with drinking water that contained 100 mg (AA100), $200 \mathrm{mg}$ (AA200), or $300 \mathrm{mg}$ (AA300) ascorbic acid per litre drinking water, or $400 \mathrm{mg}$ (BT400), $800 \mathrm{mg}$ (BT800), $1200 \mathrm{mg}$ (BT1200) betaine per litre drinking water, respectively. The composition of the experimental diets is shown in Table 1, which were formulated as per NRC (1994) specifications.

Table 1 Formula and nutrient composition of experimental diet (as-fed basis)

\begin{tabular}{|c|c|c|}
\hline Ingredients (g/kg) & Starter, 1 - 21 days & Finisher, 22 - 42 days \\
\hline Maize & 503.0 & 588.2 \\
\hline Soybean meal & 335.0 & 180.0 \\
\hline Wheat & 50.0 & 90.0 \\
\hline Tallow & 40.0 & 50.0 \\
\hline Whole soybean & - & 4.10 \\
\hline Fish meal & 30.0 & 10.0 \\
\hline Limestone & 10.4 & 9.8 \\
\hline Dicalcium phosphate & 8.3 & 7.0 \\
\hline Common salt & 2.0 & .5 \\
\hline Mineral premix ${ }^{a}$ & 5.5 & 5.0 \\
\hline Vitamin premix ${ }^{\mathrm{b}}$ & 8.0 & 6.0 \\
\hline L-Lysine & 3.1 & 4.5 \\
\hline DL-Methionine & 3.9 & 3.5 \\
\hline Threonine & - & 0.11 \\
\hline Choline chloride (50\%) & 0.8 & 1.0 \\
\hline Tryptophan & - & 0.4 \\
\hline \multicolumn{3}{|l|}{ Nutrient composition } \\
\hline Metabolizable energy (MJ/kg) & 13.4 & 13.3 \\
\hline Crude protein & 229.9 & 185.1 \\
\hline Calcium & 8.7 & 8.3 \\
\hline Available P & 5.0 & 4.6 \\
\hline Lysine & 14.1 & 11.2 \\
\hline Methionine & 6.5 & 5.8 \\
\hline
\end{tabular}

\footnotetext{
${ }^{a}$ Mineral premix supplied per kilogram of diet: Mn: 110000 mg; Zn: 100000 mg; Fe: 40000 mg; Se: 300 mg; Cu: 5000 mg; I: 1250 mg; Co: 250 mg.

${ }^{\mathrm{b}}$ Vitamin premix supplied per kilogram of diet: vitamin A: $10000000 \mathrm{IU}$; vitamin $\mathrm{D}_{3:} 5000000 \mathrm{IU}$; vitamin E: 20 $000 \mathrm{IU}$; vitamin K: 3000 mg; vitamin $B_{1}: 2000$ mg; vitamin $B_{2}: 6000$ mg; vitamin $B_{6}: 3000$ mg;

vitamin $B_{12}$ : $16000 \mathrm{mg}$; pantothenic acid: $13000 \mathrm{mg}$; folic acid: $1500 \mathrm{mg}$; niacin: $50000 \mathrm{mg}$; biotin:100 mg
} 
Ascorbic acid (ascorbic acid 100\%, Northeast Pharmaceutical Group Co., Ltd, China) solutions were prepared by dissolving $100 \mathrm{mg}, 200 \mathrm{mg}$ and $300 \mathrm{mg}$ powder in $1000 \mathrm{~mL}$ water. Betaine (betaine $97 \%$ coated, Beta-Key, Excentials, Netherlands) solutions were prepared by dissolving $400 \mathrm{mg}, 800 \mathrm{mg}$ and $1200 \mathrm{mg}$ powder in $1000 \mathrm{~mL}$ water. Meat ducks were reared by conventional methods in a normal environment $\left(22^{\circ} \mathrm{C}\right.$ to $26^{\circ} \mathrm{C}$ ) during the starter and growing phases (days 1 to 21). Drinking water that contained ascorbic acid or betaine was provided during a period of artificial heat stress that corresponded to the finishing phase (days 22 to 42). After applying heat stress $\left(11: 00\right.$ to $17: 00,33{ }^{\circ} \mathrm{C}$ to $43{ }^{\circ} \mathrm{C}$, automatic control, relative humidity $70 \%$ ) on 21 days of the finishing period, the normal environment was maintained.

All animals were reared with continuous lighting and ad libitum feeding during the entire rearing period. During the experimental period, bodyweight gain, feed intake and feed conversion ratio (feed intake/body weight gain) were investigated as productivity measurement variables.

All ducks were fasted for 10 hours from midnight the day before the last experimental day. Three ducks with similar bodyweights were randomly selected from each of the pens and anesthetized with a $1.5 \%$ mixture of halothane in oxygen. Approximately $5 \mathrm{~mL}$ of blood was collected via cardiac puncture in plain tubes (Greine Co. Ltd, Australia) using a syringe and 23 gauge needles. Serum was separated from blood by centrifugation at $4{ }^{\circ} \mathrm{C}$ and $3000 \mathrm{rpm}$ for $20 \mathrm{~min}$. Blood levels of glucose, triglyceride, total cholesterol, high density lipoprotein-cholesterol (HDL-C) and low density lipoprotein-cholesterol (LDL-C) as well as aspartate aminotransferase (AST, EC 2.6.1.1) and alanine aminotransferase (ALT, EC 2.6.1.2) enzymes are measured as activity using an automated analysis instrument (Hitachi 917, Japan) and diagnostic kits (Sigma Chemical Co, St. Louis, MO, USA). For haematological indices, total red blood cell (RBC) counts, haematocrit (HCT), haemoglobin $(\mathrm{Hb})$, mean corpuscular volume (MCV), mean corpuscular haemoglobin concentration (MCHC), red cell distribution width (RDW), platelet count (PLT), platelet crit (PCT) and mean platelet volume (MPV) were measured using an automated blood cell counter (Forcyte, Oxford Science, USA). Additionally, blood electrolytes, such as sodium, potassium and chloride (VetScan i-STAT 1 handheld analyser, Abaxis, USA), and blood gas (RAPIDChem 744/754 blood gas analysers, Siemens, USA) were measured.

Statistical analyses of all data were performed using Statistical Package for Social Sciences (SPSS) Windows 21.0 (SPSS Inc., Chicago, IL, USA). After conducting a one-way analysis of variance (ANOVA) for mean values for each treatment group, Duncan's multiple range test was performed to confirm significant differences at $95 \%$ confidence level $(P<0.05)$.

\section{Results and Discussion}

The bodyweight gain, feed intake and feed conversion ratio of ducks in the treatment groups were significantly better than those of the control group under heat stress during the 21 days $(P<0.05)$ (Table 2). The body weight of ducks in the AA300 and BT1200 groups was higher at 22 - 42 days than that of the control group by $272 \mathrm{~g}(9.4 \%)$ and $258 \mathrm{~g}(8.9 \%)$, respectively. Additionally, the bodyweight gain of ducks in the AA300 group was higher than those in the AA100 and AA200 groups $(P<0.05)$. Similarly, the bodyweight gain of ducks in the BT1200 group was higher than that of ducks in the BT400 and BT800 groups $(P<0.05)$ The feed intake of ducks in the AA300 and BT1200 groups was $282 \mathrm{~g} \mathrm{(4.9 \% )}$ and $267 \mathrm{~g} \mathrm{(4.6 \% ),} \mathrm{respectively,}$ which were significantly higher than that observed in the control group (5 $802 \mathrm{~g}, P<0.05)$. Feed conversion ratio of ducks was not different between treatment groups. This result is consistent with previous studies that found that the supplementation of ascorbic acid or betaine in drinking water to broiler chickens under heat stress improved their growth performance (Kadim et al., 2008; Ratriyanto et al., 2009).

The blood HDL-C, total cholesterol, triglycerides, LDL-C, blood sugar levels, and liver function-related enzymes, AST and ALT of meat ducks fed under heat stress are shown in Table 3. Except for blood HDL-C levels, the blood levels in ducks in the various AA and BT treatment groups were significantly lower than those of the control group $(P<0.05)$. The levels of low blood biomarkers, except for HDL-C in the AA and BT groups, can be attributed to the higher bioenergy metabolism in the AA and BT groups compared with the control (Park et al., 2013; Yoon et al., 2013). The provision of ascorbic acid to broiler chickens that are exposed to a high-temperature environment can relieve heat stress through constantly maintaining the of ALT and AST (McKee et al., 1997). Because the provision of drinking water that contained ascorbic acid or betaine decreased blood lipid and sugar levels in ducks exposed to heat stress, that might indicate that blood lipid level is reduced owing to a lower threshold of 3-hydroxy-3-methylglutaryl-coenzyme A, a cholesterol biosynthesis enzyme, and the degradation of bile acid, which inhibits cholesterol resynthesis in the liver (Yakhkeshi et al., 2012). This result suggests that providing drinking water that contains ascorbic acid or betaine may help meat ducks to relieve heat stress by enhancing blood lipid and energy metabolism. 
Table 2 Effect of drinking water with betaine and ascorbic acid on growth performance in ducks under heat stress

\begin{tabular}{|c|c|c|c|c|c|c|c|c|}
\hline & \multirow{2}{*}{ Control } & \multicolumn{3}{|c|}{ Ascorbic acid (mg/L) } & \multicolumn{3}{|c|}{ Betaine (mg/L) } & \multirow{2}{*}{ SEM } \\
\hline & & 100 & 200 & 300 & 400 & 800 & 1200 & \\
\hline \multicolumn{9}{|c|}{ Bodyweight g } \\
\hline Initial & 48 & 49 & 49 & 49 & 49 & 48 & 48 & 2.061 \\
\hline 1 - 21 days & 1330 & 1326 & 1352 & 1336 & 1325 & 1343 & 1343 & 72.06 \\
\hline 22 - 42 days & $2886^{c}$ & $3025^{b}$ & $3058^{b}$ & $3158^{a}$ & $3034^{b}$ & $3061^{b}$ & $3144^{a}$ & 125.8 \\
\hline \multicolumn{9}{|c|}{ Feed intake $\mathbf{g}$} \\
\hline 1 - 21 days & 1849 & 1830 & 1860 & 1859 & 1843 & 1852 & 1853 & 81.57 \\
\hline 22 - 2 days & $3990^{b}$ & $4173^{a}$ & $4158^{a}$ & $4225^{a}$ & $4183^{a}$ & $4156^{a}$ & $4210^{a}$ & 155.7 \\
\hline 1 - 42 days & $5802^{b}$ & $6002^{a}$ & $6018^{a}$ & $6084^{a}$ & $6024^{a}$ & $6008^{\mathrm{a}}$ & $6069^{\mathrm{a}}$ & 218.2 \\
\hline \multicolumn{9}{|c|}{ Feed conversion ratio (feed intake/body weight gain) } \\
\hline 1 - 21 days & 1.39 & 1.38 & 1.38 & 1.39 & 1.39 & 1.38 & 1.38 & 0.071 \\
\hline 22 - 42 days & 2.01 & 1.98 & 1.97 & 1.92 & 1.98 & 1.96 & 1.93 & 0.106 \\
\hline
\end{tabular}

$\overline{a, b, c}$ Means with no common superscript within the same row are significantly different $(P<0.05)$

Table 3 Effect of drinking water with betaine and ascorbic acid on blood lipid profile, glucose, aspartate aminotransferase and alanine aminotransferase activities in ducks under heat stress

\begin{tabular}{lcccccccc}
\hline & & \multicolumn{9}{c}{ Ascorbic acid (mg/L) } & \multicolumn{3}{c}{ Betaine (mg/L) } & \multirow{2}{*}{ SEM } \\
\cline { 3 - 7 } & Control & $\mathbf{1 0 0}$ & $\mathbf{2 0 0}$ & $\mathbf{3 0 0}$ & $\mathbf{4 0 0}$ & $\mathbf{8 0 0}$ & $\mathbf{1 2 0 0}$ & \\
\hline TC (mg/dL) & $303.6^{\mathrm{a}}$ & $265.3^{\mathrm{c}}$ & $272.3^{\mathrm{b}}$ & $246.2^{\mathrm{d}}$ & $258.4^{\mathrm{c}}$ & $261.9^{\mathrm{c}}$ & $253.2^{\mathrm{c}}$ & 3.856 \\
HDL-C (mg/dL) & $75.39^{\mathrm{e}}$ & $88.95^{\mathrm{d}}$ & $89.45^{\mathrm{d}}$ & $120.0^{\mathrm{a}}$ & $93.60^{\mathrm{c}}$ & $95.68^{\mathrm{c}}$ & $102.9^{\mathrm{b}}$ & 2.797 \\
TG (mg/dL) & $141.5^{\mathrm{a}}$ & $105.7^{\mathrm{b}}$ & $100.7^{\mathrm{c}}$ & $79.15^{\mathrm{d}}$ & $112.3^{\mathrm{b}}$ & $115.2^{\mathrm{b}}$ & $83.18^{\mathrm{d}}$ & 4.370 \\
LDL-C (mg/dL) & $172.3^{\mathrm{a}}$ & $129.8^{\mathrm{c}}$ & $148.3^{\mathrm{b}}$ & $93.39^{\mathrm{d}}$ & $132.6^{\mathrm{c}}$ & $148.3^{\mathrm{b}}$ & $127.7^{\mathrm{c}}$ & 5.148 \\
Glucose (mg/dL) & $190.7^{\mathrm{a}}$ & $182.7^{\mathrm{b}}$ & $172.8^{\mathrm{d}}$ & $160.7^{\mathrm{f}}$ & $164.6^{\mathrm{e}}$ & $177.7^{\mathrm{c}}$ & $162.9^{\mathrm{f}}$ & 2.061 \\
AST (IU/L) & $86.00^{\mathrm{a}}$ & $45.33^{\mathrm{d}}$ & $44.33^{\mathrm{de}}$ & $35.23^{\mathrm{e}}$ & $51.33^{\mathrm{b}}$ & $42.67^{\mathrm{e}}$ & $48.33^{\mathrm{c}}$ & 3.550 \\
ALT (IU/L) & $47.67^{\mathrm{a}}$ & $41.33^{\mathrm{c}}$ & $37.83^{\mathrm{d}}$ & $28.67^{\mathrm{f}}$ & $44.17^{\mathrm{b}}$ & $33.67^{\mathrm{e}}$ & $35.83^{\mathrm{e}}$ & 1.253 \\
\hline
\end{tabular}

$\overline{\mathrm{a}, \mathrm{b}, \mathrm{c}, \mathrm{d}, \mathrm{e}, \mathrm{f}}$ Means with no common superscripts within the same row are significantly different $(P<0.05)$. TC: total cholesterol, HDL-C: high density lipoprotein, TG: triglyceride, LDL-C: low density lipoprotein, AST: aspartate aminotransferase,

ALT: alanine aminotransferase

Red blood cell and platelet count profiles were greater in the treatment groups compared with the control group $(P<0.05)$ (Table 4). The highest RBC and platelet counts were found in AA300 and BT1200 $(P$ $<0.05)$. This result indicates that drinking water containing ascorbic acid or betaine may relieve ducks' heat stress by preventing a decrease in haematological indices. It has been reported that the haematocrit level is lowered in animals that are exposed to heat stress owing to red blood cell damage, decreased red blood cell production, or decreased size of the red blood cells (Hilman et al., 1985). While a decrease in red blood cell count and haemoglobin in humans and animals causes iron deficiency anaemia under normal environmental conditions, heat stress may cause blood dilution owing to increased water intake, even without the change in plasma volume that is involved in extracellular water evaporation, ultimately resulting in decreases in red blood cell and haemoglobin levels (Türkyilmaz. 2008). 
Table 4 Effect of drinking water with betaine and ascorbic acid on red blood cell and platelet profile in ducks under heat stress

\begin{tabular}{|c|c|c|c|c|c|c|c|c|}
\hline & \multirow{2}{*}{ Control } & \multicolumn{3}{|c|}{ Ascorbic acid (mg/L) } & \multicolumn{3}{|c|}{ Betaine (mg/L) } & \multirow{2}{*}{ SEM } \\
\hline & & 100 & 200 & 300 & 400 & 800 & 1200 & \\
\hline \multicolumn{9}{|l|}{ Red blood cell } \\
\hline HCT (\%) & $31.02^{\mathrm{e}}$ & $37.61^{d}$ & $43.53^{b}$ & $47.37^{\mathrm{a}}$ & $41.31^{c}$ & $43.40^{\mathrm{b}}$ & $46.81^{a}$ & 1.044 \\
\hline $\mathrm{RBC}(\mathrm{M} / \mu \mathrm{L})$ & $3.51^{d}$ & $4.57^{c}$ & $4.43^{c}$ & $6.47^{\mathrm{a}}$ & $4.02^{c}$ & $4.14^{\mathrm{C}}$ & $5.47^{\mathrm{b}}$ & 0.183 \\
\hline $\mathrm{Hb}(\mathrm{g} / \mathrm{dL})$ & $12.18^{f}$ & $16.66^{\mathrm{e}}$ & $18.50^{d}$ & $22.42^{\mathrm{b}}$ & $17.92^{\mathrm{d}}$ & $21.21^{\mathrm{c}}$ & $25.42^{\mathrm{a}}$ & 0.795 \\
\hline MCV (fL) & $127.8^{\mathrm{e}}$ & $135.7^{\mathrm{d}}$ & $147.3^{b}$ & $149.5^{\mathrm{ab}}$ & $140.1^{c}$ & $141.3^{c}$ & $150.9^{\mathrm{a}}$ & 1.721 \\
\hline $\mathrm{MCHC}(\mathrm{g} / \mathrm{dL})$ & $37.26^{\dagger}$ & $43.25^{\mathrm{e}}$ & $52.19^{b}$ & $57.26^{\mathrm{a}}$ & $49.51^{\mathrm{cd}}$ & $51.16^{\mathrm{bc}}$ & $55.25^{\mathrm{a}}$ & 1.407 \\
\hline RDW (\%) & $4.31^{\mathrm{e}}$ & $5.48^{d}$ & $6.35^{\mathrm{C}}$ & $8.02^{\mathrm{a}}$ & $6.05^{\mathrm{c}}$ & $6.71^{\mathrm{C}}$ & $7.77^{\mathrm{b}}$ & 0.257 \\
\hline \multicolumn{9}{|l|}{ Platelets } \\
\hline $\mathrm{PLT}(\mathrm{K} / \mu \mathrm{L})$ & $24.28^{9}$ & $35.69^{f}$ & $38.25^{\mathrm{e}}$ & $47.33^{b}$ & $42.06^{\mathrm{d}}$ & $44.37^{\mathrm{c}}$ & $50.13^{a}$ & 1.594 \\
\hline РСТ (\%) & $0.03^{\mathrm{e}}$ & $0.05^{c}$ & $0.06^{\mathrm{abc}}$ & $0.06^{\mathrm{ab}}$ & $0.05^{\mathrm{bc}}$ & $0.05^{\mathrm{bc}}$ & $0.07^{\mathrm{a}}$ & 0.001 \\
\hline MPV (fL) & $8.33^{f}$ & $10.22^{\mathrm{e}}$ & $14.20^{\mathrm{c}}$ & $18.31^{\mathrm{a}}$ & $14.41^{c}$ & $14.37^{\mathrm{c}}$ & $1666^{\mathrm{b}}$ & 0.645 \\
\hline
\end{tabular}

$\overline{a, b, c, d, e, f, g}$ Means with no common superscript within the same row are significantly different $(P<0.05)$

$\mathrm{HCT}$ : haematocrit, $\mathrm{Hb}$ : haemoglobin, MCV: mean corpuscular volume,

MCHC: mean corpuscular haemoglobin concentration, RDW: red cell distribution width, PLT: platelet count,

PCT: platelet crit, MPV: mean platelet volume

Blood electrolyte concentrations in treatment groups were significantly greater than those in the control group $(P<0.05)$ (Table 5). In particular, sodium $\left(\mathrm{Na}^{+}\right)$, potassium $\left(\mathrm{K}^{+}\right)$, and chloride $\left(\mathrm{Cl}^{-}\right)$concentrations in the AA300 group were higher than the control group. This result indicates that providing drinking water that contains ascorbic acid or betaine to meat ducks under heat stress may relieve their stress by maintaining constant blood electrolyte concentrations, thus controlling osmotic pressure. Blood $\mathrm{Na}^{+}, \mathrm{K}^{+}$, and $\mathrm{Cl}^{-}$ concentrations are decreased in poultry and buffalo owing to heat stress (Kumar et al., 2010). It has also been reported that the sodium-potassium ATP pump is important for the in vivo energy metabolism and the maintenance of intracellular water balance, while osmotic pressure control through betaine may enhance cell proliferation (Zulkifli et al., 2004). The decrease in blood $\mathrm{Cl}^{-}$in the heat stress control group might be because more $\mathrm{Cl}^{-}$ions are required to accelerate the acidification of blood to normalize blood $\mathrm{pH}$ following the development of respiratory alkalosis, since heat stress increases blood pH (Borges et al., 2007).

Table 5 Effect of drinking water with betaine and ascorbic acid on blood electrolytes ( $\mathrm{mmol} / \mathrm{L}$ ) in ducks under heat stress

\begin{tabular}{|c|c|c|c|c|c|c|c|c|}
\hline & \multirow{2}{*}{ Control } & \multicolumn{3}{|c|}{ Ascorbic acid (mg/L) } & \multicolumn{3}{|c|}{ Betaine (mg/L) } & \multirow{2}{*}{ SEM } \\
\hline & & 100 & 200 & 300 & 400 & 800 & 1200 & \\
\hline Sodium & $140.6^{d}$ & $148.1^{\mathrm{c}}$ & $150.6^{\mathrm{b}}$ & $152.6^{\mathrm{a}}$ & $147.2^{\mathrm{c}}$ & $150.1^{\mathrm{b}}$ & $150.2^{\mathrm{b}}$ & 7.070 \\
\hline Potassium & $3.80^{\mathrm{d}}$ & $4.57^{\mathrm{b}}$ & $5.01^{\mathrm{a}}$ & $5.11^{\mathrm{a}}$ & $4.50^{\mathrm{bc}}$ & $4.37^{\mathrm{c}}$ & $4.55^{\mathrm{b}}$ & 0.093 \\
\hline Chloride & $107.2^{\mathrm{b}}$ & $113.4^{\mathrm{a}}$ & $114.2^{\mathrm{a}}$ & $115.2^{\mathrm{a}}$ & $113.4^{\mathrm{a}}$ & $115.2^{\mathrm{a}}$ & $114.6^{\mathrm{a}}$ & 5.610 \\
\hline
\end{tabular}

$\overline{a, b, c, d}$ Means with no common superscript within the same row are significantly different $(P<0.05)$

Blood $\mathrm{pH}$ values in the treatment groups were lower than those in the control group, particularly in AA300, which had the lowest blood $\mathrm{pH}(P<0.05)$. On the other hand, blood gas concentrations in treatment groups were significantly greater than those in the control group $(P<0.05$, Table 6$)$. This result indicates that 
providing drinking water that contains ascorbic acid or betaine may relieve heat stress by maintaining constant blood gas concentrations through the biological functions of betaine (Park \& Kim, 2016). Although heat stress can decrease blood $\mathrm{pCO}_{2}$ (partial pressure of carbon dioxide) in broiler chickens, maintaining $\mathrm{pCO}_{2}$ at an appropriate level during heat stress is necessary since poultry remove $\mathrm{CO}_{2}$ continuously by panting through the respiratory system to reduce their body temperature by evaporating water from their lungs (Hilman et al., 1985; Zulkifli et al., 2004; Mahmoudnia \& Madani, 2012).

Table 6 Effect of drinking water with betaine and ascorbic acid (milligrams per litre) on blood $\mathrm{pH}$ and blood gas concentration in duck under heat stress

\begin{tabular}{lcccccccc}
\hline & \multirow{2}{*}{ Control } & \multicolumn{3}{c}{ Ascorbic acid (mg/L) } & \multicolumn{3}{c}{ Betaine (mg/L) } & \multirow{2}{*}{ SEM } \\
\cline { 3 - 7 } & & $\mathbf{1 0 0}$ & $\mathbf{2 0 0}$ & $\mathbf{3 0 0}$ & $\mathbf{4 0 0}$ & $\mathbf{8 0 0}$ & $\mathbf{1 2 0 0}$ & \\
\hline $\mathrm{pH}$ & $7.43^{\mathrm{a}}$ & $7.41^{\mathrm{ab}}$ & $7.40^{\mathrm{b}}$ & $7.35^{\mathrm{c}}$ & $7.40^{\mathrm{b}}$ & $7.40^{\mathrm{b}}$ & $7.39^{\mathrm{b}}$ & 0.410 \\
$\mathrm{PCO}_{2}(\mathrm{~mm} \mathrm{Hg})$ & $41.72^{\mathrm{d}}$ & $45.78^{\mathrm{c}}$ & $49.01^{\mathrm{a}}$ & $49.27^{\mathrm{a}}$ & $48.21^{\mathrm{ab}}$ & $47,49^{\mathrm{bc}}$ & $47.07^{\mathrm{bc}}$ & 1.723 \\
$\mathrm{HCO}_{3}(\mathrm{mmol} / \mathrm{L})$ & $21.23^{\mathrm{b}}$ & $26.01^{\mathrm{a}}$ & $27.12^{\mathrm{a}}$ & $26.67^{\mathrm{a}}$ & $25.66^{\mathrm{a}}$ & $27.21^{\mathrm{a}}$ & $26.60^{\mathrm{a}}$ & 0.502 \\
$\mathrm{AnGap}(\mathrm{mmol} / \mathrm{L})$ & $14.73^{\mathrm{c}}$ & $17.32^{\mathrm{b}}$ & $18.90^{\mathrm{a}}$ & $18.87^{\mathrm{a}}$ & $17.02^{\mathrm{ab}}$ & $17.88^{\mathrm{b}}$ & $18.47^{\mathrm{a}}$ & 0.379 \\
$\mathrm{TCO}_{2}(\mathrm{mmol} / \mathrm{L})$ & $21.50^{\mathrm{d}}$ & $27.65^{\mathrm{b}}$ & $29.40^{\mathrm{a}}$ & $29.37^{\mathrm{a}}$ & $29.01^{\mathrm{a}}$ & $26.55^{\mathrm{c}}$ & $28.27^{\mathrm{a}}$ & 0.711 \\
\hline
\end{tabular}

$\overline{a, b, c, d}$ Means with no common superscript within the same raw are significantly different $(P<0.05)$

\section{Conclusions}

The results of this study indicate that providing drinking water that contains ascorbic acid at 300 milligrams per litre or betaine at 1200 milligrams per litre to meat ducks that are exposed to heat stress in summer can relieve heat stress and improve productivity by controlling blood biomarkers, haematological indices, blood electrolytes and blood $\mathrm{pH}$.

\section{Acknowledgements}

This study was funded by Agenda for the 2015 Rural Development Administration (PJ010088), Republic of Korea.

\section{Authors' Contributions}

$\mathrm{K}-\mathrm{HS}, \mathrm{K}-\mathrm{H}$ and B-SP designed the study, and H-JP, Y-SC and H-SL performed the biochemical determination, and $\mathrm{KHU}, \mathrm{BSP}$ wrote the paper with input from all authors.

\section{Conflict of Interest Declaration}

The authors have no conflicts of interest to declare.

\section{References}

Awad, A.L, Fahim, H.N., Ibrahim, A.F. \& Beshara, M.M., 2014. Effect of dietary betaine supplementation on productive and reproductive performance of domyati ducks under summer conditions. Egypt. Poult. Sci. 34, 453-474.

Bang, H.T., Hwangbo, J., Kang, H.K. \& Park, B.S., 2015. Effect of different feeding times using a diet containing betaine on production, blood profile and a short chain fatty acid in meat ducks exposed to a scorching heat wave. Korean J. Oil Chem. 32, 427-438.

Borges, S.A., Fischer da Silva, A.V. \& Maiorka, A., 2007. Acid-base balance in broilers. WPSA 63, 73-81.

Boyera, N., Galey, I. \& Bernard, B.A., 1998. Effect of vitamin C and its derivatives on collagen synthesis and cross-linking by normal human fibroblasts. Int. J. Cosmet. Sci. 20, 151-158.

Del Vesco, AP., Gasparino, E., Grieser, D.O., Zancanela, V., Gasparin, F.R.S., Constantin, J. \& Neto, A.R., 2014. Effects of methionine supplementation on the redox state of acute heat stress-exposed quails. J. Anim. Sci. 92, 806-815.

Gaughan, J.B., Bonner, S.L., Loxton, I. \& Mader, T.L., 2013. Effects of chronic heat stress on plasma concentration of secreted heat shock protein 70 in growing feedlot cattle. J. Anim. Sci. 91, 120-129.

Hilman, PE., Scot, N.R. \& Tienhoven, A.V., 1985. Physiological, responses and aption to hot and cold environments. In: M.K. Yousef (ed). Stress Physiology in Livestock. Vol III Poultry. CRC, Boca Raton, FL. 2-71.

Hwangbo, J., Bang, H.T., Kang, H.K. \& Park, H.K., 2015. Effect of dietary betaine on short chain fatty acid and blood profile in meat duck exposed to extreme heat stress. Korean J. Oil Chem. 32, 394-404.

Kadim, I.T., Al-Qamshui, B.H.A., Mahgoub, O., Al-Marzooqi, W. \& Johnson, E.H., 2008. Effect of seasonal temperatures and ascorbic acid supplementation on performance of broiler chickens maintained in closed and open-sided houses. Int. J. Poult. Sci. 7, 655-660. 
Kumar, B.V.S., Singh, G. \& Meur, S.K., 2010. Effects of addition of electrolyte and ascorbic acid in feed during heat stress in buffaloes. Asian-Austral. J. Anim. Sci. 23, 880-888.

Mahmoudnia, N. \& Madani, Y., 2012. Effect of betaine on performance and carcass composition of broiler chicken in warm weather - a review. Int. J. Agri. Sci. 2, 675-683.

McKee, J.S., Harrison, P.C. \& Riskowski, G.L., 1997. Effects of supplemental ascorbic acid on the energy conversion of broiler chicks during heat stress and feed withdrawal. Poult. Sci. 76, 1278-1286.

National Research Council, 1994. Nutrient Requirements of Poultry. National Academy Press, Washington, DC, USA.

Park, S.O. \& Kim, W., 2016. Effects of betaine on biological functions in meat-type ducks exposed to heat stress. Poult. Sci. 96, 1212-1218.

Park, S.O., Hwangbo, J., Ryu, C.M., Park, B.S., Chae, H.S., .., Choi, Y.H., 2013. Effects of extreme heat stress on growth performance, lymphoid organ, IgG and cecum microflora of broiler chickens. Int. J. Agr. Biol. 15,1204-1208.

Ratriyanto, A., Mosenthin, R., Bauer, E. \& Eklund, M., 2009. Metabolic, osmoregulatory and nutritional functions of betaine in monogastric animals. Asian-Austral. J. Anim. Sci. 22, 1461-1476.

Sahin, K., Sahin, N. \& Kucuk, O., 2003. Effects of chromium, and ascorbic acid supplementation on growth, carcass traits, serum metabolites, and antioxidant status of broiler chickens reared at a high ambient temperature. Nutr. Res. 23, 225-238.

Sharma, S., Ramesh, K., Hyder, I., Uniyal, S., Yadav, V.P., ..., Mitra, A., 2013. Effect of melatonin administration on thyroid hormones, cortisol and expression profile of heat shock proteins in goats (Capra hircus) exposed to heat stress. Small Rumin. Res. 112, 216-223.

Türkyilmaz, M.K., 2008. The effect of stocking density on stress reaction in broiler chickens during summer. Turk. J. Vet. Anim. Sci. 32, 31-36.

Yakhkeshi, S., Rahimi, S. \& Hemati Matin, H.R., 2012. Effects of yarrow (Achillea millefolium L.), antibiotic and probiotic on performance, immune response, serum lipids and microbial population of broilers. J. Agr. Sci. Technol. 14, 799-810.

Yoon, J.S., Kang, H.K., Park, S.O., Park, B.S., Hwangbo, J., ..., Choi, Y.H., 2013. Effects of inverse lighting and diet with soy oil on growth performance and short chain fatty acid of broilers exposed to extreme heat stress. Korean J. Oil Chem. 30, 127-138.

Zulkifli, I., Mysahra, S.A. \& Jin, L.Z., 2004. Dietary supplementation of betaine (Betafin®) and response to high temperature stress in male broiler chickens. Asian-Austral. J. Anim. Sci. 17, 244-249. 